Original Article

\title{
Comparative Distalization Effects Of Conventional Pendulum Appliance And Bone Anchored Pendulum Appliance
}

\author{
Crystal Runa Soans ${ }^{1}$, Ashutosh Shetty ${ }^{2}$, Murali P.S. ${ }^{3}$, Azhar Mohammed, U.S. Krishna Nayak ${ }^{5}$, \\ Keerthan Shashidhar ${ }^{6}$ \\ 1, 3, ${ }^{4}$ Lecturer, ${ }^{2,5}$ Professor, ${ }^{6}$ Post Graduate, Department of Orthodontics and Dentofacial Orthopaedics, A.B. Shetty \\ M emorial Institute of Dental Sciences, M angalore, Karnataka.
}

Corresponding Author : Crystal Runa Soans, Lecturer, Department of Orthodontics and Dentofacial Orthopaedics, A.B. Shetty M emorial Institute of Dental Sciences, Deralakatte, M angalore, Karnataka, E-M ail : drcrystalsoans@ gmail.com

Received :22.07.2017
$\begin{aligned} & \text { Review Completed }: 29.11 .2017 \\ & \text { Accepted :02.02.2018 }\end{aligned}$
Keywords : Angles Class II
Malocclusion, Molar Distalization,
Conventional Pendulum
Appliance, Bone Anchored
PendulumAppliance

\begin{tabular}{|c|}
\hline Access this article online \\
\hline Quick Response Code \\
\hline
\end{tabular}

\begin{abstract}
:
Introduction: The introduction of intraosseous screws as temporary orthodontic anchorage devices has proved successful in achieving sufficient molar distalization without major anchorage loss in Class II malocclusions. Bone-anchored pendulum appliance is used to obtain an effective and compliance-free molar distalization without anchorage loss.
\end{abstract}

AimsAnd Objectives: This prospective study was designed to evaluate and compare the skeletal and dentoalveolar effects produced by 2 types of pendulum appliance with different anchorage modalities - the Bone anchored pendulum appliance (BAPA) and Conventional pendulum appliance (CPA) in subjects with Angle's Classll malocclusion.

\begin{abstract}
M aterials and M ethods: BAPA group consisted of 5 patients with mean age, $16.4 \pm 1$.5years. The CPA group consisted of 5 patients with mean age, $16.6 \pm 1.1$ years. Lateral cephalograms $\&$ dental casts were obtained at pre-treatment stage $\&$ after achieving Class I molar relation. Dentoalveolar, skeletal, soft tissue measurements and dental cast measurement were recorded $\&$ compared between the groups.

Results and Conclusions: Successful distalization was achieved in both groups in a mean period of 6.2 months for BAPA and 5.2 months for CPA. It was concluded that, both theBAPA and CPA were effective for the distalization of maxillary molars. Though the distal molar movements obtained were similar between the BAPA and the CPA groups, anchorage loss was observed with the CPA in the form of premolar mesialization\& incisor proclination, whereas absence of anchorage loss, significant spontaneous distal premolar movement, and distal incisor movement was observed with the BAPA, making it a viable choice compared to the CPA.
\end{abstract}

\section{Introduction}

The etiology, components and orthodontic management of Class II malocclusion have been a subject of frequently differing philosophies among practitioners. Treatment modalities for correction of Class II malocclusion have included extraction of teeth, extraoral forces, interarch elastics, functional appliances, noncompliance techniques with Herbst appliance, and, more recently, intra-arch maxillary molar distalizing techniques. ${ }^{1}$

Distalization of molars has become a popular nonextraction treatment alternative to get upper molars into a final Class I relationship.The Pendulum appliance, developed by Hilgers ${ }^{2}$, has become one of the more popular non compliance appliance designs. Howevercertain side effectslike anchorage loss in the form of increased overjet and molar tipping were evident. ${ }^{3}$

The introduction of intraosseous screws as temporary orthodontic anchorage devices has proved successful in achieving sufficient molar distalization without major anchorage loss. ${ }^{4,5}$ Kircelli et $\mathrm{al}^{6}$ designed the Bone-anchored pendulum appliance (BAPA), to obtain an effective and compliance-free molar distalization without anchorage loss.

The present study intends to evaluate and compare the dentoalveolar and skeletal effects obtained with Pendulum appliance using (a) conventional anchorage and (b) bone anchorage. 
The study was conducted with the following aims and objectives:

1. To evaluate the distalization of the maxillary molars, and the movement of teeth anterior to maxillary first molars, in both CPA and BAPA

2. To compare the dentoalveolar and skeletal effects obtained with Bone anchored pendulum appliance and Conventional pendulum appliance.

\section{Materials and Methods}

Source of Data:

This study was conducted in the Department of Orthodontics and Dentofacial Orthopaedics, A.B. Shetty M emorial Institute of Dental Sciences, M angalore.

The sample of this study consisted of 10 subjects seeking orthodontic treatment with Angle's Class II malocclusion requiring maxillary molar distalization with an average or horizontal growth pattern, in the age group of 14-18yrs.

An informed consent was taken and the 10 subjects were divided into 2 groups.

GroupA represented 5 orthodontic patients in whom maxillary molar distalization was attempted with a Bone Anchored Pendulum Appliance (BAPA) (Fig 1, 2)

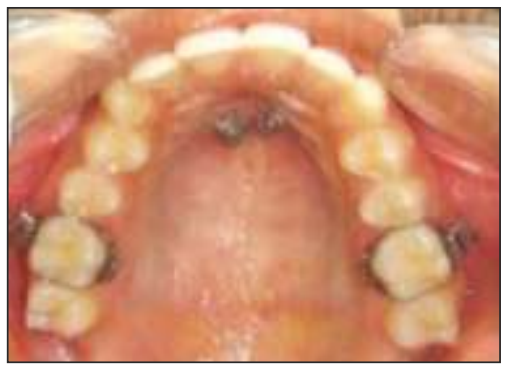

Fig. 1 : Placement of Intraosseous screws intraorally

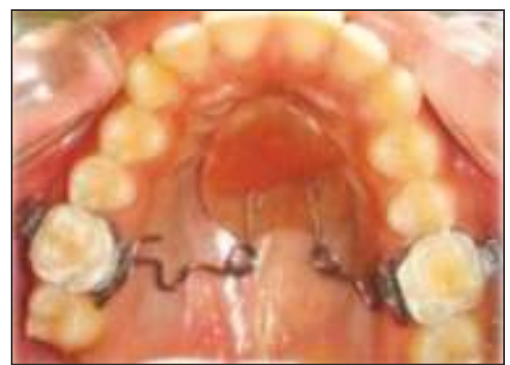

Fig. 2 : Bone Anchored Pendulum Appliance placed intraorally
Group B represented 5 orthodontic patients in whom maxillary molar distalization was attempted with a Conventional Pendulum Appliance (CPA) (Fig3)

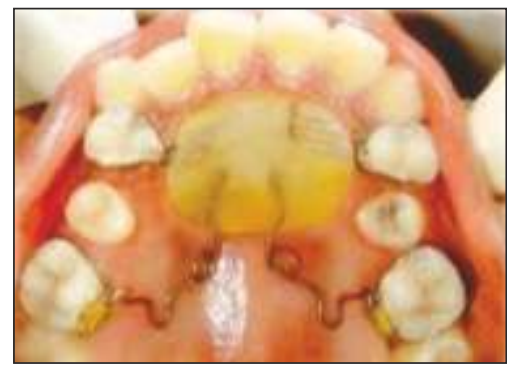

Fig. 3 : Conventional Pendulum Appliance placed intra orally

Inclusion criteria:

1. Patients with good oral hygiene.

2. Patients with average or horizontal growth pattern.

3. Patients with permanent dentition and Class II molar relation.

4. Moderate space deficiency in the maxillary arch and minimal or no crowding in the mandibular arch

5. Patients with fully erupted second molars.

Exclusion criteria:

1. Uncooperative patients

2. Poor oral hygiene

3. Skeletal Class II relation

\section{Methodology}

This prospective study was designed to evaluate and compare the skeletal and dentoalveolar effects produced by 2 types of pendulum appliances with different anchorage modalities -the Bone anchored pendulum appliance (BAPA) and Conventional pendulum appliance (CPA) in subjects with Angle Class II malocclusion.

The BAPA group consisted of 5 patients ( 4 girls, 1 boy; mean age, 16.4 \pm 1 .5years). The CPA group consisted of 5 patients (4 girls, 1 boy; mean age, 16.6 \pm 1.1 years).The treatment results of BAPA group were compared with that ofthe CPA group.

The maxillary second molars were fully erupted in all patients in both the groups. The maxillary third molars were extracted in 8 of the total 10 patients selected for this study. In the remaining subjects, germectomy was not 
advised as the tooth buds were highly placed above the second molar roots.

\section{Cephalometric analysis an Dental Cast M easurements}

Lateral cephalograms and dental casts were obtained at pre treatment and after achieving Class I molar relation (T2) to assess dentoalveolar, skeletal and soft tissue changes. Cephalometric analysis was done on the cephalograms using various parameters (Fig 3,4,5). M easurements were also recorded on the dental casts (Fig 6).

\section{Skeletal : \\ 1. SNB (') \\ 2. SNB (') \\ 3. ANB (') \\ 4. FMA (') \\ 5. SnGoGn (') \\ 6. PTV-A Point $(\mathrm{mm})$ \\ 7. PTV -Palatal plane (')}

\section{Soft tissue :}

8. Upper lip to E-Plane (mm)

9. Lower lip to E-Plane $(\mathrm{mm})$

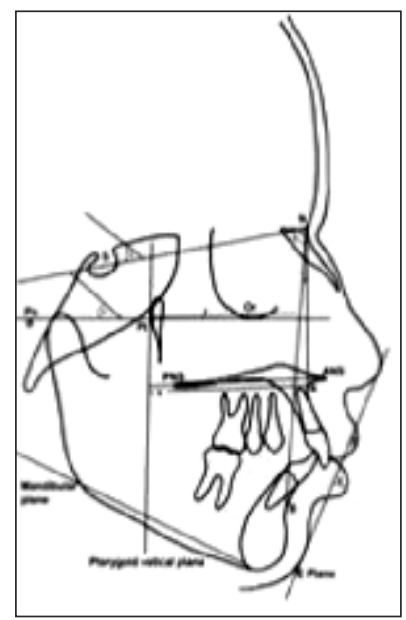

Fig. 4 : Skeletal and Soft tissue measurements

\section{Dental -linear sagital ( $\mathrm{mm}$ )}

1. Maxillary first molar-PTV

2. Maxillary second premolar PTV

3. M axillary first premolar -PTV

4. Maxillary incisor -PTV

5. M andibular first molar -PTV

- Overjet

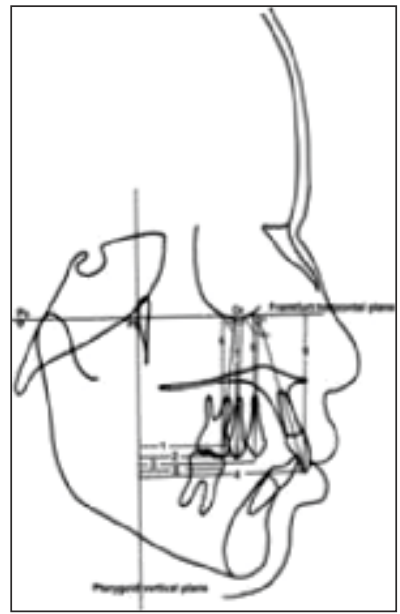

Fig. 5 : Dental linear (Sagittal) measurements
Dental -linear vertical

6. Maxillary first molar -FH

7. Maxillary second premolar -FH

8. Maxillary first premolar -FH

9. Maxillary incisor - $\mathrm{FH}$

\section{Overbite}

- Dental - angular (')

10. Maxillary first molar - FH

11. Maxillary second premolar -FH

12. Maxillary first premolar $-\mathrm{FH}$

13. Maxillary incisor $-\mathrm{FH}$

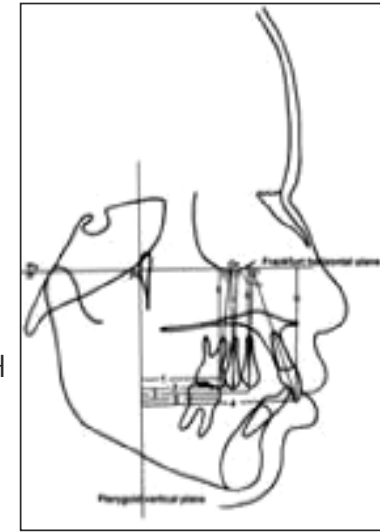

Fig. 6 : Dental linear and Dental angular measurements

1. Intermolar distance ( $\mathrm{mm}$ )

2. Length of total arch perimeter $(\mathrm{mm})$

3. Length of anterior arch perimeter $(\mathrm{mm})$

4. Maxillary first molar MPP (')

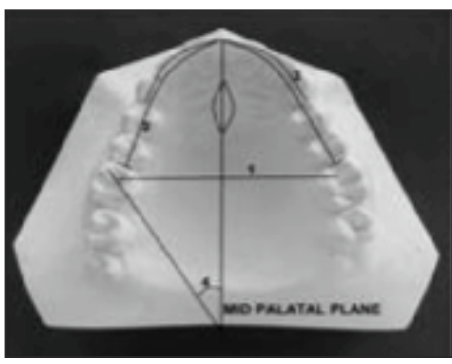

Fig 7. : Dental Cast M easurements

\section{Statistical Analysis}

Data obtained was analyzed using Statistical Package for Social Sciences. Analysis was done using SPSS version 14 The total number of samples in each group were 10/5 in BAPA group and 5 in CPA group) Comparison of mean scores were done for various parameters. Paired sample test for angular and linear skeletal measurements before and after treatment (T2-T1), Independent samples test for comparison ofangular and linear skeletal measurements before and after treatment (T2-T1) between the groups were used. A p-value of $\varangle .05$ was set to be statistically significant.

\section{Results}

Clinically successful distalization was achieved in both groups in a mean period of 6.2 months for BAPA and 5.2 months for CPA (Table 1). The $p$ value for the same is $\varangle$ 05 
Table 1: Duration of months

The data collected presented with the following findings:

\begin{tabular}{|c|c|c|c|c|c|c|}
\hline Group & $\mathrm{N}$ & Minimum & M aximum & Mean & $\begin{array}{c}\text { Std. } \\
\text { Deviation }\end{array}$ & p-value \\
\hline BAPA & 5 & 5.5 & 7 & 6.20 & .57 & \multirow{2}{*}{$\mathbf{0 . 0 2 4}$} \\
\hline CPA & 5 & 4.5 & 6 & 5.20 & .57 & \\
\hline
\end{tabular}

Angular and linear skeletal measurements: (Table2,3) (graph 1)

Table 2 : Paired sample test for angular and linear skeletal measurements

\begin{tabular}{|c|c|c|c|c|c|c|}
\hline \multirow[t]{2}{*}{ Group } & & \multicolumn{2}{|c|}{ T1 } & \multicolumn{2}{|c|}{ T2 } & \multirow[b]{2}{*}{$p$-value } \\
\hline & & Mean & SD & M ean & SD & \\
\hline \multirow{8}{*}{ BAPA } & SNA & 81.20 & 1.79 & 81.80 & 2.17 & 0.07 \\
\hline & SNB & 79.40 & 1.52 & 79.40 & 2019 & 1 \\
\hline & ANB & 1.80 & 0.84 & 2.40 & 0.89 & 0.07 \\
\hline & FMA & 23.60 & 1.14 & 26.00 & 2.45 & 0.06 \\
\hline & Sn Go Gn & 30.60 & 1.82 & 31.80 & 1.30 & 0.033 \\
\hline & PTV-A & 56.40 & 3.91 & 56.00 & 3.24 & 0.374 \\
\hline & PTV-B & 50.80 & 2.95 & 50.20 & 3.27 & 0.07 \\
\hline & PTV-PP & 1.20 & 0.84 & 1.80 & 0.45 & 0.07 \\
\hline \multirow{8}{*}{ CPA } & SNA & 79.80 & 3.19 & 79.80 & 2.95 & 1 \\
\hline & SNB & 77.60 & 2.70 & 78.00 & 2.55 & 0.62 \\
\hline & ANB & 2.20 & 0.84 & 1.80 & 1.10 & 0.477 \\
\hline & FMA & 25.00 & 5.24 & 26.20 & 3.63 & 0.284 \\
\hline & Sn Go Gn & 31.00 & 3.39 & 32.80 & 2.17 & 0.088 \\
\hline & PTV-A & 50.60 & 3.65 & 51.40 & 3.36 & 0.242 \\
\hline & PTV-B & 42.40 & 7.80 & 42.60 & 7.64 & 0.799 \\
\hline & PTV-PP & 1.80 & 0.84 & 1.40 & 0.96 & 0.099 \\
\hline
\end{tabular}

Table 3 : Independent samples test for angular and linear skeletal measurements (T2-T1)

\begin{tabular}{|c|c|c|c|c|c|}
\hline & \multicolumn{2}{|c|}{ BAPA } & \multicolumn{2}{c|}{ CPA } & \multirow{2}{*}{} \\
\cline { 1 - 5 } & Mean & SD & Mean & SD & -value \\
\hline SNA & 0.60 & 0.55 & 0.00 & 1.41 & 0.416 \\
\hline SNB & 0.00 & 0.71 & 0.40 & 1.67 & 0.642 \\
\hline ANB & 0.60 & 0.55 & -0.40 & 1.14 & 0.115 \\
\hline FM A & 2.40 & 2.07 & 1.20 & 2.17 & 0.397 \\
\hline Sn Go Gn & 1.20 & 0.84 & 1.80 & 1.79 & 0.516 \\
\hline PTV-A & -0.40 & 0.89 & 0.80 & 1.30 & 0.128 \\
\hline PTV-B & -0.60 & 0.55 & 0.20 & 1.64 & 0.332 \\
\hline PTV-Palatal Plane & 0.60 & 0.55 & -0.40 & 0.42 & $\mathbf{0 . 0 1 2}$ \\
\hline
\end{tabular}

Graph 1 : Comparison of Pre- Treatment and Post Distalization skeletal (linear and angular) measurements between the two groups(T2-T1)

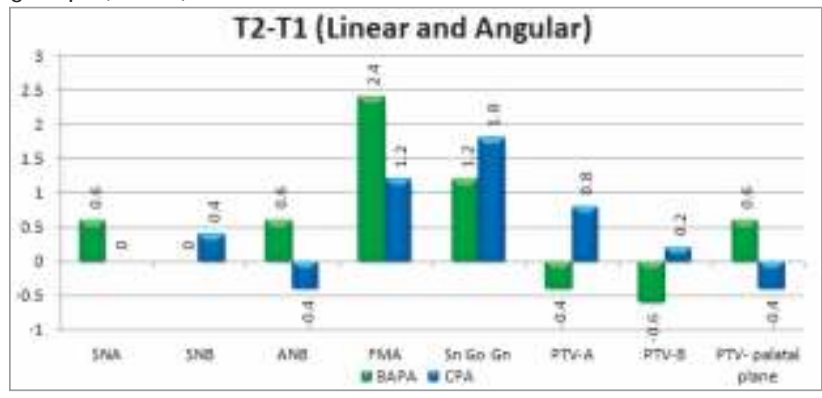

Soft Tissue Measurements

Table 4 : Paired sample test for soft tissue measurements

\begin{tabular}{|c|c|c|c|c|c|c|}
\hline Group & & \multicolumn{2}{|c|}{ T1 } & \multicolumn{2}{c|}{ T2 } & \multirow{2}{*}{-value } \\
\cline { 3 - 7 } & & M ean & SD & M ean & SD & -val \\
\hline \multirow{2}{*}{ BAPA } & U LIP E PLANE & -2.70 & 3.03 & -2.20 & 3.11 & 0.089 \\
\cline { 2 - 7 } & L LIP E PLANE & 0.80 & 3.70 & 1.30 & 2.82 & 0.326 \\
\hline \multirow{2}{*}{ CPA } & U LIP E PLANE & -2.20 & 2.28 & -1.20 & 1.92 & 0.298 \\
\cline { 2 - 7 } & L LIP E PLANE & 1.00 & 1.73 & 2.60 & 1.34 & $\mathbf{0 . 0 0 3}$ \\
\hline
\end{tabular}

Table 5 : Independent samples test for soft tissue measurements

\begin{tabular}{|l|c|c|c|c|c|}
\hline & \multicolumn{2}{|c|}{ BAPA } & \multicolumn{2}{c|}{ CPA } & \multirow{2}{*}{-value } \\
\cline { 2 - 5 } & Mean & SD & Mean & SD & -val \\
\hline U LIP E PLANE & 0.50 & 0.50 & 1.00 & 1.87 & 0.580 \\
\hline L LIP E PLANE & 0.50 & 1.00 & 1.60 & 0.55 & 0.063 \\
\hline
\end{tabular}

Graph 2 : Comparison of Pre- Treatment and Post Distalization soft tissue measurements between the two groups (T2-T1)

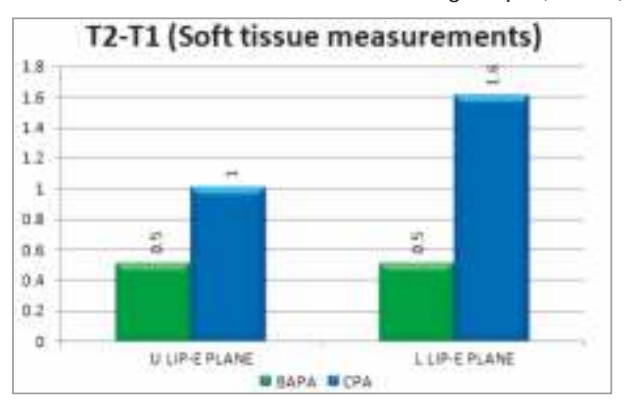

\section{Dental linear measurements:}

Sagittal

Table 6 : Paired sample test for dental linear (sagittal) measurements

\begin{tabular}{|c|c|c|c|c|c|c|}
\hline \multirow[t]{2}{*}{ Group } & & \multicolumn{2}{|c|}{ T1 } & \multicolumn{2}{|c|}{ T2 } & \multirow[b]{2}{*}{$p$-value } \\
\hline & & Mean & SD & Mean & SD & \\
\hline \multirow{6}{*}{1} & Ma6-PVT & 32.60 & 3.58 & 28.60 & 3.36 & $\varangle 0.00$ \\
\hline & Ma5-PVT & 36.40 & 3.36 & 33.40 & 3.65 & 0.005 \\
\hline & Ma4-PVT & 44.60 & 4.51 & 42.20 & 4.38 & 0.024 \\
\hline & Ma1-PVT & 63.60 & 4.67 & 61.00 & 4.42 & 0.019 \\
\hline & Mn6-PVT & 32.00 & 4.00 & 31.80 & 3.83 & 0.374 \\
\hline & OVERJET & 4.80 & 1.79 & 3.40 & 1.14 & 0.108 \\
\hline & $\begin{array}{l}\text { Ma6-PVT } \\
\end{array}$ & 30.40 & 2.41 & 26.40 & 1.95 & 0.003 \\
\hline & $\begin{array}{l}\text { Ma5-PVT } \\
\end{array}$ & 30.80 & 4.66 & 31.20 & 5.26 & 0.704 \\
\hline & Ma4-PVT & 37.80 & 4.55 & 41.20 & 6.46 & 0.096 \\
\hline & Ma1-PVT & 55.00 & 5.92 & 59.20 & 6.38 & 0.022 \\
\hline & Mn6-PVT & 28.00 & 4.00 & 28.40 & 3.91 & 0.178 \\
\hline & OVERJET & 4.00 & 0.71 & 5.60 & 1.67 & 0.078 \\
\hline
\end{tabular}


Table 7 : Independent samples test for dental linear (sagittal) measurements(T2-T1)

\begin{tabular}{|c|c|c|c|c|c|}
\hline \multirow{2}{*}{ Saggital } & \multicolumn{2}{|c|}{ BAPA } & \multicolumn{2}{c|}{ CPA } & \multirow{2}{*}{-value } \\
\cline { 2 - 5 } & Mean & SD & Mean & SD & -val \\
\hline Ma6-PVT & -4.00 & 0.71 & -4.00 & 1.41 & 1 \\
\hline Ma5-PVT & -3.00 & 1.22 & 0.40 & 2.19 & 0.022 \\
\hline Ma4-PVT & -2.40 & 1.52 & 3.40 & 3.51 & 0.017 \\
\hline Ma1-PVT & -2.60 & 1.52 & 4.20 & 2.59 & 0.001 \\
\hline M n6-PVT & -0.20 & 0.45 & 0.40 & 0.55 & 0.094 \\
\hline OVERJET & -1.40 & 1.52 & 1.60 & 1.52 & 0.014 \\
\hline
\end{tabular}

Graph 3 : Comparison of Pre- Treatment and Post Distalization dental linear (sagittal) measurements between the two groups (T2-T1)

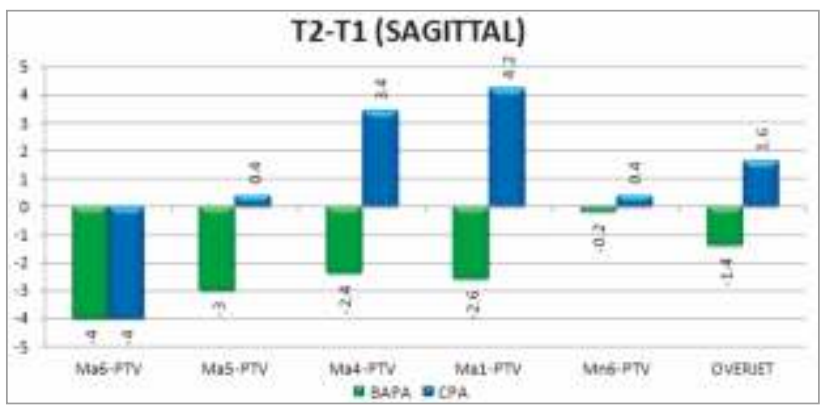

\section{Dental linear measurements:}

Vertical

Table 8 : Paired sample test for dental linear (vertical) measurements

\begin{tabular}{|c|c|c|c|c|c|c|}
\hline Group & Dentolinear & \multicolumn{2}{|c|}{ T1 } & \multicolumn{2}{|c|}{ T2 } & \\
\cline { 3 - 7 } & & Mean & SD & M ean & SD & p-value \\
\hline \multirow{4}{*}{ BAPA } & Ma6-FH & 47.40 & 3.36 & 49.00 & 3.74 & 0.003 \\
\cline { 2 - 7 } & Ma5-FH & 48.40 & 3.85 & 49.00 & 3.94 & 0.07 \\
\cline { 2 - 7 } & Ma4-FH & 49.20 & 4.09 & 49.20 & 4.32 & 1 \\
\cline { 2 - 7 } & Ma1-FH & 51.20 & 4.87 & 52.40 & 5.27 & 0.07 \\
\cline { 2 - 7 } & OVERBITE & 3.80 & 1.10 & 2.60 & 0.89 & 0.004 \\
\hline \multirow{4}{*}{ CPA } & Ma6-FH & 45.40 & 3.58 & 47.00 & 3.67 & 0.003 \\
\cline { 2 - 7 } & Ma5-FH & 47.20 & 3.63 & 47.80 & 2.59 & 0.426 \\
\cline { 2 - 7 } & Ma4-FH & 48.00 & 3.39 & 50.00 & 4.06 & 0.022 \\
\cline { 2 - 7 } & Ma1-FH & 52.00 & 4.69 & 53.00 & 3.00 & 0.326 \\
\cline { 2 - 7 } & OVERBITE & 3.20 & 1.30 & 3.20 & 0.84 & 1 \\
\hline
\end{tabular}

Table 9 : Independent samples test for dental linear (vertical) measurements(T2-T1)

\begin{tabular}{|c|c|c|c|c|c|}
\hline \multirow{2}{*}{ Vertical } & \multicolumn{2}{|c|}{ BAPA } & \multicolumn{2}{c|}{ CPA } & \multirow{2}{*}{-value } \\
\cline { 2 - 5 } & Mean & SD & M ean & SD & -vann \\
\hline Ma6-FH & 1.60 & 0.55 & 1.60 & 0.55 & 1 \\
\hline Ma5-FH & 0.60 & 0.55 & 0.60 & 1.52 & 1 \\
\hline Ma4-FH & 0.00 & 1.00 & 2.00 & 1.22 & $\mathbf{0 . 0 2 2}$ \\
\hline Ma1-FH & 1.20 & 1.10 & 1.00 & 20.00 & 0.8429 \\
\hline OVERBITE & -1.20 & 0.45 & 0.00 & 1.22 & 0.074 \\
\hline
\end{tabular}

Graph 4 : Comparison of Pre- Treatment and Post Distalization dental linear (vertical) measurements between the two groups (T2-T1)

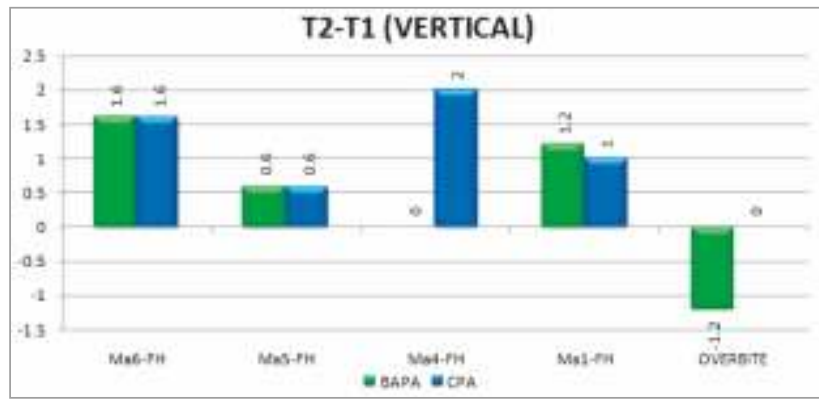

\section{Dental angular measurements}

Table 10: Paired sample test for dental angular measurements

\begin{tabular}{|c|c|c|c|c|c|c|}
\hline \multirow[t]{2}{*}{ Group } & \multirow[t]{2}{*}{ Angular } & \multicolumn{2}{|c|}{ T1 } & \multicolumn{2}{|c|}{ T2 } & \multirow[b]{2}{*}{ p-value } \\
\hline & & Mean & SD & M ean & SD & \\
\hline \multirow{4}{*}{ BAPA } & Ma6-FH & 84.40 & 1.52 & 76.20 & 2.95 & 0.002 \\
\hline & Ma5-FH & 88.00 & 2.35 & 81.00 & 4.69 & 0.023 \\
\hline & $\mathrm{Ma4-FH}$ & 90.00 & 0.71 & 86.00 & 4.47 & 0.092 \\
\hline & Mal-FH & 120.20 & 8.47 & 113.60 & 10.33 & 0.003 \\
\hline \multirow{4}{*}{ CPA } & Ma6-FH & 82.00 & 8.46 & 72.60 & 6.66 & 0.004 \\
\hline & Ma5-FH & 84.60 & 8.05 & 83.80 & 7.79 & 0.294 \\
\hline & Ma4-FH & 86.20 & 6.06 & 93.00 & 10.15 & 0.038 \\
\hline & Mal-FH & 144.60 & 8.38 & 122.00 & 8.00 & 0.003 \\
\hline
\end{tabular}

Table 11 : Independent samples test for dental angular measurements (T2-T1)

\begin{tabular}{|c|c|c|c|c|c|}
\hline \multirow{2}{*}{ Angular } & \multicolumn{2}{|c|}{ BAPA } & \multicolumn{2}{c|}{ CPA } & \multirow{2}{*}{ p-value } \\
\cline { 2 - 5 } & Mean & SD & M ean & SD & 0.565 \\
\hline Ma6-FH & -8.20 & 2.59 & -9.40 & 3.65 & 0.017 \\
\hline M a5-PVT & -7.00 & 4.36 & -0.80 & 1.48 & 0.017 \\
\hline Ma4-FH & -4.00 & 4.06 & 6.80 & 4.97 & 0.006 \\
\hline Ma1-FH & -6.60 & 2.30 & 7.40 & 2.51 & $<0.001$ \\
\hline
\end{tabular}

Graph 5 : Comparison of Pre- Treatment and Post Distalization dental angular measurements between the two groups (T2-T1)

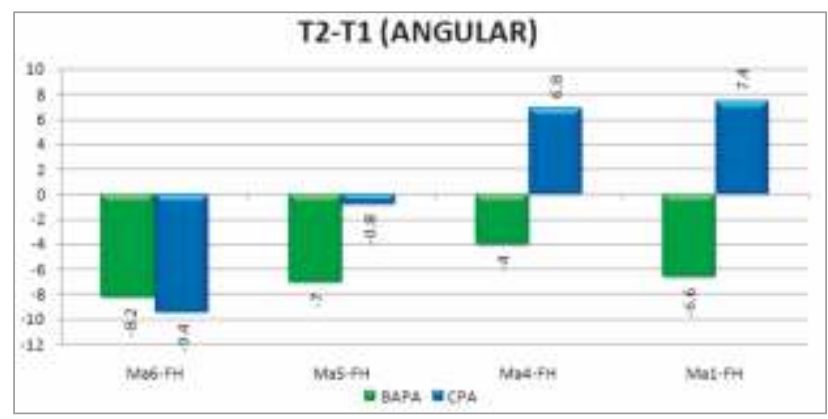




\section{Dental cast measurements}

Table 12 : Paired sample test for dental cast measurements

\begin{tabular}{|c|c|c|c|c|c|c|}
\hline Group & Cast measurements & \multicolumn{2}{|c|}{ T1 } & \multicolumn{2}{c|}{ T2 } & p- \\
\cline { 3 - 7 } & & Mean & SD & M ean & SD & value \\
\hline \multirow{4}{*}{ BAPA } & Inter - molar distance & 47.40 & 2.30 & 49.40 & 2.61 & 0.047 \\
\cline { 2 - 7 } & Total arch perimeter & 79.80 & 6.02 & 89.80 & 5.40 & 0.007 \\
\cline { 2 - 7 } & Anterior Arch perimeter & 49.60 & 3.36 & 53.40 & 3.58 & 0.003 \\
\cline { 2 - 7 } & M a6-M PP & 33.40 & 2.70 & 36.00 & 2.55 & 0.007 \\
\hline \multirow{4}{*}{ CPA } & Inter - molar distance & 46.40 & 1.95 & 48.00 & 2.74 & 0.078 \\
\cline { 2 - 7 } & Total arch perimeter & 77.00 & 2.92 & 87.40 & 4.62 & 0.002 \\
\cline { 2 - 7 } & Anterior Arch perimeter & 49.60 & 3.78 & 54.00 & 4.24 & 0.001 \\
\cline { 2 - 7 } & M a6-M PP & 32.20 & 2.49 & 36.40 & 2.30 & 0.001 \\
\hline
\end{tabular}

Table 13 : Independent samples test for dental cast measurements(T2-T1)

\begin{tabular}{|c|c|c|c|c|c|}
\hline \multirow{2}{*}{} & \multicolumn{2}{|c|}{ BAPA } & \multicolumn{2}{c|}{ CPA } & \multirow{2}{*}{} \\
\cline { 2 - 5 } & Mean & SD & M ean & SD & p-value \\
\hline Inter - molar distance & 2.00 & 1.58 & 1.60 & 1.52 & 0.694 \\
\hline Total arch perimeter & 10.00 & 4.30 & 10.40 & 3.36 & 0.874 \\
\hline Anterior arch perimeter & 3.80 & 1.30 & 4.40 & 1.14 & 0.461 \\
\hline M a6-M PP & 2.60 & 1.14 & 4.20 & 1.10 & 0.053 \\
\hline
\end{tabular}

Graph 6 : Comparison of Pre- Treatment and Post Distalization dental cast measurements between the two groups (T2-T1)

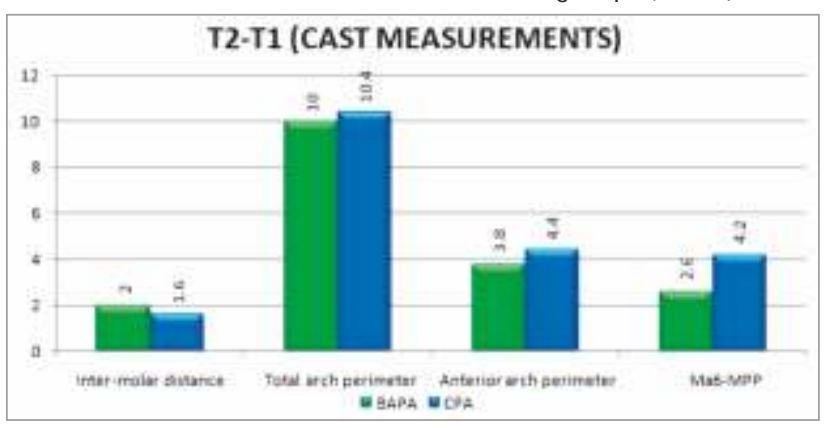

\section{Discussion}

The pendulum appliance has experienced wide spread clinical use, and various studies have demonstrated its skeletal and dentoalveolar effects. ${ }^{7.89}$ It has two main advantages over headgear and Class II elastics. ${ }^{10}$ One being, distalization occurs without any cooperation problems on the part of the patients and the other being, only one activation period is needed for the process to be successful. However, associated collateral effects like anterior anchorage loss, which represented $30-43 \%$ of the space created between molars and premolars, was a constant finding with use of this appliance as shown in various studies. $^{5,7,8,10}$

The introduction of bone anchors as anchorage devices has been a great revolution in orthodontics. Several types of anchors have been used such as conventional osseo integrated implants and, more recently, mini-implants, length-reduced palatal implants etc. Elimination of the osseo integration period (2-6 months), wider range of application sites, simple surgical procedures, and decreased cost make intra osseous screws the preferable anchorage device In the present study we used 2 screws based on the study by Kircelli et al ${ }^{7}$ to increase the success rate. The site of intraosseous placement was the paramedian region of the palate with a mean bone depth of $10.57 \mathrm{~mm}$.

Although the dentofacial effects of the BAPA and CPA have been demonstrated separately in previous studies, ${ }^{8,9,11,1213}$ ${ }^{15}$ comparative treatment results of the two appliance systems in terms of treatment duration, skeletal changes, and soft tissue response and tooth movement with cephalometric and dental cast measurements have not been reported previously.

In our study, the maxillary molars in both groups were distalized successfully to Class I relationships with minimal patient compliance. The average distalization periods were 6.2 months for the BAPA and 5.2 months for CPA. The difference in time taken for treatment was statistically significant. $(p=0.024)$.There was significant amount of distal molar movement in both the BAPA and CPA group. The average distance of molar movement between the 2 groups was similar; $4.0 \pm 0.71 \mathrm{~mm}$ in BAPA group and $4.0 \pm 1.41 \mathrm{~mm}$ in CPA group.

Intraoral distalizing appliances act on the dental crowns at a certain distance from the centre of resistance of the molars, and therefore distal tipping is expected. This tipping is similar to that produced by the cervical headgear. In this study the amount of molar tipping observed were $8.20^{\circ} \pm 2.59^{\circ}$ in the BAPA group and $9.40^{\circ} \pm 3.56^{\circ}$ in the CPA group. The difference between the groups was statistically not significant. $(p>0.05)$

While most of the studies ${ }^{7,8,12, \text { and } 16}$ on pendulum appliance have reported molar intrusion, some have reported molar 
extrusion as well. In our study, there was a small amount of vertical change seen in the maxillary first molars of both groups. The BAPA group showed molar extrusion of $1.6 \pm 0$. $5 \mathrm{~mm}$ and the CPA group showed molar intrusion of $1.60 \pm 0.5 \mathrm{~mm}$. These values were statistically significant $(p=0.003)$. Distalization techniques tend to increase the extrusion of the molars, ${ }^{17,18}$ and also the bite opening seen in most distalization studies have been attributed to the extrusion of the maxillary first molars. ${ }^{13,19}$ This could explain the molar extrusion and reduction in overbite with the BAPA.

Loss of anchorage was measured at the maxillary $1^{\text {st }}$ premolars and incisors. Premolar and incisor movements were quite different between the 2 groups. In the BAPA group, both the first $\left(2.4 \pm 1.52 \mathrm{~mm} / 4.0^{\circ} \pm 4.06\right)$ and second $\left(3.00 \pm 1.22 \mathrm{~mm} / 7.0 \pm 4.36^{\circ}\right)$ premolars were significantly $(p \varangle 0.05)$ distalized and distally tipped spontaneously. The maxillary incisors were significantly $(p \varangle 0.001)$ retroclined $\left(6.6^{\circ} \pm 2.3^{\circ}\right)$ and retracted by $2.6 \pm 1.52 \mathrm{~mm}$.A significant $(p \varangle 0.05)$ decrease in over jet $(1.4 \pm 1.52 \mathrm{~mm})$ was also observed. The reactive forces arising from the pendulum springs were directly resisted by intraosseous screws, and the premolars and incisors drifted distally due to the stretch of transeptal fibres during the distalization period. These movements could contribute favourably to the overall treatment time.On the other hand, the CPA group showed significant loss of anchorage with mesial tipping and mesial movement of first premolars $\left(6.8^{\circ} \pm 4.97 \% 3.4 \pm 3.51 \mathrm{~mm}\right)$, and a small but significant amount of extrusion $(2.0 \pm 1.22 \mathrm{~mm})$.The incisors were significantly $(p<0.001)$ proclined by $7.4^{\circ} \pm 2.51 \%$ $4.2 \pm 2.59 \mathrm{~mm}$ and there was significant increase in over jet $(1.6 \pm 1.52 \mathrm{~mm})$.The use of a Nance button to reinforce anterior anchorage has been suggested by many, but reports state that it does not serve as absolute anchorage during and after molar distalization. ${ }^{6,20}$ The anchorage unit is unable to completely resist mesial forces thereby proclining the maxillary incisors and increasing the overjet. Study by Burkhardt et $\mathrm{al}_{,}{ }^{20}$ support our findings of anchorage loss by incisor tipping.

\section{Skeletal values and soft tissue effects}

Pendulum appliance primarily affects the dentition, but there are simultaneous indirect effects on the skeletal and soft tissue structures. In our study, a significant counter clockwise inclination of the palatal plane by an angle of $0.6^{\circ} \pm 0.55^{\circ}$ was recordedin the BAPA group. This was confirmed by previous observations by Bussick and M cNamara ${ }^{21}$ In the CPA group there was a small amount of decrease in the palatal plane. $\left(0.4^{\circ} \pm 0.42^{\circ}\right)$.

The mandibular plane rotated clockwise in both BAPA and CPA group.The FMA increased by $2.4^{\circ} \pm 2.07^{\circ}$ in the BAPA group and $1.2^{\circ} \pm 2.17^{\circ}$ in the CPA group. The SnGoGn increased by $1.2^{\circ} \pm 0.84^{\circ}$ in the BAPA group and $1.8^{\circ} \pm 1.79^{\circ}$ in CPA group. Similar results were demonstrated by other studies with conventional pendulum. ${ }^{7.9}$ The clockwise mandibular rotation can be attributed to the maxillary molars moving distally into the wedge of occlusion and to the cusp interferences. ${ }^{11}$

Studies on conventional pendulum have shown lip protrusion as a result of the incisor tipping..$^{7.9}$ In this study, a small increase in value was seen from lower lip to esthetic line in the CPA group $(1.6 \pm 0.5 \mathrm{~mm})$, which was found to be statistically significant $(p \varangle 0.05)$.

\section{Dental cast measurements}

The transverse changes measured on the dental casts showed a significant increase in the inter molar distance for BAPA group. There was also an increase seen in the CPA group but this value was not statistically significant $(p>0.05)$. There was a significant increase in the total arch perimeter in both groups $(p \varangle 0.05)$.

Significant distopalatal rotation of the maxillary first molars was seen in both groups. The CPA group showed more rotation $\left(4.2^{\circ} \pm 1.1^{\circ}\right)$ as compared to the BAPA group $\left(2.6^{\circ} \pm 1.14^{\circ}\right)$, but comparison of mean between the groups was not statistically significant. Distalizing coils act lingually at the center of resistance of the molars, and thus there is a tendency toward distopalatal rotation with a possibility towards molar crossbite. ${ }^{7,23}$ This explains the rotation of the molars as seen in our study. 


\section{Conclusions}

The following conclusions can be drawn from the study:

- Both the BAPA and CPA are effective for the distalization of maxillary molars and the establishment of a Class I molar relationship.

- The distal molar movements obtained were similar between the BAPA and the CPA groups.

- Anchorage loss was observed with the CPA in the form of premolar mesialization and incisor proclination.

\section{References}

1. Haas AJ. Headgear therapy: the most efficient way to distalize molars. SeminOrthod. 2006; 6:79-90.

2. Hilgers JJ. The pendulum appliance for class II non- compliance therapy.J ClinOrthod. 1992; 26:700-713.

3. Joseph AA, Butchard CJ. An evaluation of the pendulum distalizing appliance. SeminOrthod. 2000; 6:129-135.

4. Gianelly AA. Distal movement of the maxillary molars. Am J Orthod. 1998: 114:66-72.

5. Gelgor IE, Buyukyilmaz T, Karaman Al. Use of the intraosseous screw for unilateral upper molar distalization and found well balanced occlusion. Head and face medicine. 2006; 2: 38-42.

6. Gelgor IE, Buyukyilmaz T, Karaman Al. Comparison of 2 distalization systems supported by intraosseous screws. Am J Orthod DentofacialOrthop 2007; 131: 161.e1-161.e8.

7. Kircelli BH, Zafer OP, Kircelli C. Maxillary molar distalization with a bone-anchored pendulum appliance. Angle Orthod. 2006; 76:650-9.

8. Angelieri F, Rodrigues de Almeida R, Rodrigues de Almeida M, Fuziy A Dentoalveolar and skeletal changes associated with the pendulum appliance followed by fixed orthodontic treatment. Am J OrthodDentofacialOrthop. 2006; 129:520-7.

9. Onçag G, Seçkin O, Dinçer B, Arikan F. Osseointegrated implants with pendulum springs for maxillary molar distalization: a cephalometric study. Am J OrthodDentofacialOrthop. 2007; 131:16-26.

10. Kanomi R. Mini- implant for orthodontic anchorage. J ClinOrthod. 1999: 31:763-767.

11. Chiu PP, M cNamara JA, Franchi I. A comparison of two intraoral molar distalization appliances: distal jet vs pendulum. Am J OrthodDentofacialOrthop. 2005; 128:353-65.

12. Fuziy A, Rodrigues de Almeida R, Janson G, Angelieri F, Pinzan A. Sagittal, vertical, and transverse changes consequent to maxillary molar distalization with the pendulum appliance. Am J OrthodDentofacialOrthop. 2006; 130:502-10.

13. Patel M P, Janson G, Henriques JF, de Almeida RR, de Freitas M R, Pinzan A, de Freitas KM. Comparative distalization effects of Jones jig and
On the contrary, absence of anchorage loss, significant spontaneous distal premolar movement, and distal incisor movement was observed with the BAPA making it a viable choice compared to the CPA.To overcome the limitations associated with this study, future studies with larger sample size, both after treatment and in retention phase, are needed.

pendulum appliances. Am J OrthodDentofacialOrthop. 2009; 135:336-42.

14. Fudalej P, Antoszewska J. Are orthodontic distalizers reinforced with the temporary skeletal anchorage devices effective? Am J OrthodDentofacialOrthop. 2011; 139:722-9.

15. Costa A, Pasta G, Bergamaschi G. Intra oral hard and soft tissue depths for temporary anchorage devices. SeminOrthod. 2005; 11:10-15.

16. Roberts WE, Smith RK, Silberman Y, M ozsary PG, Smith RS. Osseous adaptation to continuous loading of rigid endosseous implants. Am J Orthod 1984; 86:95-111.

17. King KS, Lam EW, Faulkner M G, Hoe G, M ajor PW. Vertical bone volume in the paramedian palate of adolescents: A computed tomography study. Am J OrthodDentofacialOrthop. 2007; 132:7388.

18. Nalcaci R, Bicakci AA, Ozan F. Noncompliance screw supported maxillary molar distalization in a parallel manner. Korean J Orthod. 2010; 40: 250-259.

19. Ngantung V, Nanda RS, Bowman SJ. Post treatment evaluation of the distal jet appliance. Am J OrthodDentofacialOrthop. 2001; 120: 17885.

20. Burkhardt DR, M cNamara JA Jr, Bacetti T. M axillary molar distalization or mandibular enhancement: a cephalometric comparison of comprehensive orthodontic treatment including the pendulum and herbst appliances. Am J OrthodDentofacialOrthop. 2003; 123: 108-16.

21. Bussick TJ, McNamara JA. Dentoalveolar and skeletal changes associated with the pendulum appliance. American Journal of Orthodontics and DentofacialOrthopedics. 2000 Mar 31;117(3):33343.

22. Wong AM K, Rabie ABM , Hagg u. The use of pendulum in the treatment of Class II malocclusion. Br Dent J. 1999; 187: 367-70.

23. Patel M P, Janson G, Henriques JF, de Almeida RR, de Freitas M R, Pinzan A, de Freitas KM. Comparative distalization effects of Jones jig and pendulum appliances. Am J OrthodDentofacialOrthop. 2009; $135: 336-42$. 